\title{
Some aspects on modelling of the $\beta$-phase depletion behaviour under different oxide growth kinetics in HVOF CoNiCrAlY coatings
}

\author{
H. Chen ${ }^{\mathrm{a}, *}$ and D. G. McCartney ${ }^{\mathrm{b}}$
}

${ }^{a}$ Department of Mechanical, Materials and Manufacturing Engineering, Faculty of Science and Engineering, University of Nottingham Ningbo China, Ningbo 315100, China

${ }^{b}$ Advanced Materials Research Group, Faculty of Engineering, University of
Nottingham, University Park, Nottingham NG7 2RD, UK

\begin{abstract}
In this paper, $\beta$-phase depletion behaviour of free-standing high velocity oxy-fuel (HVOF) thermally sprayed CoNiCrAlY coatings was studied. Microstructural analysis showed a twophase microstructure of $\gamma$-Ni matrix and $\beta$-NiAl secondary phase after heat treatment. Fine grains were found around the sprayed particle boundaries and coarse grains were retained as the original particle structure, with grain sizes varying from 2 to $0.5 \mu \mathrm{m}$ or even less for both phases. The $\beta$-phase depletion behaviour was investigated during isothermal oxidation and was also modelled through diffusion calculations. A previously developed $\beta$-phase depletion model was utilised to study the evolution of $\beta$-phase depletion under different oxide growth kinetics. Three oxide growth models were tried: 1) Meier model, 2) thermogravimetric analysis (TGA) model, and 3) experimentally fitted oxide growth model. The oxide growth kinetics were converted to Al flux functions which were used as the boundary conditions in the DICTRA modelling. It is shown that the results obtained from the three models exhibit good agreements between the measured and predicted results for times up to $100 \mathrm{~h}$ at $1100{ }^{\circ} \mathrm{C}$, but discrepancies were noted at longer oxidation times. Further improvements on closely
\end{abstract}


modelling the oxidation kinetics and the effective diffusion behaviour are needed to minimise the discrepancies at longer oxidation times.

Keywords: HVOF spraying; MCrAlY coating; $\beta$ depletion; Diffusion; Oxidation *Corresponding Author. Tel.: +86-574-88180000-8946; Fax: +86-574-88187462.

E-mail address: Hao.Chen@nottingham.edu.cn 


\section{Introduction}

MCrAlY ( $\mathrm{M}=\mathrm{Co}, \mathrm{Ni}$, or a combination of the two $)$ are widely used as overlay coatings and as bond coats in thermal barrier coating (TBC) systems due to their excellent oxidation/corrosion resistance [1-5]. $\mathrm{Co}, \mathrm{Ni}, \mathrm{Cr}$ and $\mathrm{Al}$ are added in various amounts so that the microstructure of the coating can be tailored to meet specific requirements. Minor elements, such as Y, are also introduced to improve the oxidation resistance [6, 7]. Generally MCrAlY alloys are multi-phase materials and can comprise, for example, fcc $\gamma$-Ni, bcc $\beta$ $\mathrm{NiAl}$ and/or $\gamma^{\prime}\left(\mathrm{Ni}_{3} \mathrm{Al}\right)$ phases, depending on the compositions used [8]. During service at high temperatures, the coating oxidises and forms an outer layer of thermally grown oxides (TGO). MCrAlY coatings exhibit their protective effect owing to the fact that aluminium forms a continuous oxide layer, predominantly alumina, on the coating surface [9-12]. The aluminium consumed by forming the protective oxides is mainly from the Al-rich $\beta$ phase which acts as the $\mathrm{Al}$ reservoir in the coating. The progressive loss of $\mathrm{Al}$ causes the $\beta$ phase to deplete at the coating surface, leading to the microstructural instability of the coating [13-15]. The loss of $\beta$ phase also occurs at the coating/substrate interface due to the interdiffusion between the coating and substrate [16-27]. Eventually, the MCrAlY coating becomes non-protective when the complete loss of the $\beta$ phase occurs. Since the composition of the MCrAlY coating can be controlled to minimise the interdiffusion, the $\beta$-phase depletion at the oxide/coating interface is crucial to the durability of the coating lifetime.

Hitherto, much work has been conducted on the oxidation and hot corrosion characteristics of MCrAlY coatings manufactured by various techniques, i.e. low pressure plasma spraying (LPPS), vacuum plasma spraying (VPS) and, more recently, high velocity oxy-fuel (HVOF) thermal spraying [28-40]. It is generally recognised that the rate of Al loss and the $\beta$-phase depletion behaviour is closely related to the oxide growth kinetics at the oxide/coating interface. The modelling and prediction of the $\beta$-phase depletion thus becomes important for the assessment of coating lifetime. Work concerned on this aspect have been widely reported, 
but they are either limited to the oxide growth kinetics used or involve interdiffusion between the coating and substrate [20-27]. Since the oxide growth kinetics depends critically on the coating microstructure and deposition method and minor elements diffused from the substrate to the coating can have a significant effect on the oxidation behaviour of the coating, the accuracy of such oxide growth kinetics plays a dominant role in the lifetime prediction of MCrAlY coatings. However, the evaluation of different oxide growth kinetics on the $\beta$-phase depletion behaviour does not appear to have been previously reported.

Therefore, in this paper, the effects of different oxide growth kinetics on the evolution of $\beta$ phase depletion are examined at $1100{ }^{\circ} \mathrm{C}$. Free-standing coatings are used to model the $\beta$ phase depletion behaviour under different oxide growth kinetics and to avoid the substrate effects on the $\beta$-phase depletion. Due to the unique nature of different surface conditions in free-standing coatings, the investigation in this study focuses on the $\beta$-phase depletion kinetics at the as-sprayed rough surface. The computational thermodynamics software, Thermo-Calc, and the finite difference software, DICTRA, are used, together with a previously developed $\beta$-phase depletion model [41], to investigate the evolution of $\beta$-phase depletion. This paper is aiming at reporting the $\beta$-phase depletion behaviour under different oxidation models in free-standing MCrAlY coatings.

\section{Materials and experimental procedure}

\subsection{Materials}

Praxair CoNiCrAlY powder (CO-210-24) with a nominal composition of $\mathrm{Co}-31.7 \% \mathrm{Ni}$ $20.8 \% \mathrm{Cr}-8.1 \mathrm{Al} \%-0.5 \% \mathrm{Y}$ (all in wt\%) was deposited onto mild steel substrates by HVOF thermal spraying. The CoNiCrAlY powder has a size range of $-45+20 \mu \mathrm{m}$ with an oxygen content of $0.037 \mathrm{wt} \%$. The substrates with dimensions $60 \times 25 \times 1.8 \mathrm{~mm}^{3}$ were 800 -grit ground prior to coating deposition in order to aid coating detachment after spraying. More details of the deposition process and procedures are given elsewhere [42]. Free-standing 
coatings, with an approximate thickness of $0.5 \mathrm{~mm}$, were obtained by debonding from the substrate. The surface roughness, $\mathrm{R}_{\mathrm{a}}$, of the as-sprayed rough surface and the debonded surface were measured to be $5.6 \pm 0.8 \mu \mathrm{m}$ and $1.4 \pm 0.6 \mu \mathrm{m}$ respectively by a SURFTEST SV-600, Mitutoyo.

\subsection{Heat treatment and isothermal oxidation}

Free-standing coating samples were vacuum heat treated at $1100{ }^{\circ} \mathrm{C}$ for $2 \mathrm{~h}$ under an approximate pressure of $6.0 \times 10^{-3} \mathrm{mbar}$. The heat treatment caused the secondary phase, $\beta$, to precipitate and reduce the porosity within the coatings [39]. Isothermal oxidation tests were carried out at $1100{ }^{\circ} \mathrm{C}$ for $50 \mathrm{~h}, 75 \mathrm{~h}, 100 \mathrm{~h}$ and $250 \mathrm{~h}$ in a Carbolite furnace. Continuous weight measurements of heat treated samples during oxidation were carried out using a SDT Q600 TA Instruments thermogravimetric analyser (TGA). Samples of approximately $3 \times 3$ $\mathrm{mm}^{2}$ were put in pre-heated alumina crucibles, rough surface facing up. The furnace was set to equilibrate at $50^{\circ} \mathrm{C}$ initially, ramped $50{ }^{\circ} \mathrm{C} / \mathrm{min}$ to $1100{ }^{\circ} \mathrm{C}$ and isothermally stayed at 1100 ${ }^{\circ} \mathrm{C}$ for $95 \mathrm{~h}$. For the oxidation rate measurements the parabolic oxidation law was assumed as below:

$$
\frac{\Delta m}{A} \sim \sqrt{t}
$$

where $\Delta \mathrm{m}$ is the weight gain in grams, $\mathrm{A}$ is the surface area, taken as approximately $0.2 \mathrm{~cm}^{2}$, and $\mathrm{t}$ is time in seconds.

\subsection{Material characterisation}

The microstructures of coating cross-sections were characterised by a field-emission gun scanning electron microscope (SEM) with energy dispersive X-ray (EDX) analysis using backscatter electron model. The $\beta$-phase depletion zone and $\beta$-phase volume fraction were measured by image analysis software, ImageJ [43]. At least 5 SEM micrographs were taken 
for the $\beta$-phase depletion zone measurements and at least 10 measurements were performed in each image. The grain structure of coating cross-sections was characterised by SEM-based electron backscatter diffraction (EBSD) operated at $20 \mathrm{kV}$ with a beam current of $26 \mathrm{nA}$. The EBSD mappings were conducted at areas of $50 \mu \mathrm{m} \times 50 \mu \mathrm{m}$ using a step size of $0.1 \mu \mathrm{m}$.

\section{Modelling procedure}

\subsection{Oxidation models}

A previously developed $\beta$-phase depletion model is used here [41], where an initial $\mathrm{Al}_{2} \mathrm{O}_{3}$ scale and a corresponding $\beta$-phase depletion zone is assumed. The detailed description of the model is given elsewhere [41]. The current $\beta$ depletion model requires oxidation kinetics to be established to allow the flux of aluminium from the coating and subsequently the $\beta$-phase depletion occurs. It has been demonstrated that the oxidation kinetics have a significant influence on the evolution of the $\beta$-phase depletion [41]. Owing to different oxide growth kinetics, the aluminium flux functions at the oxide/coating interface can vary, depending on the oxidation models used. Three oxidation models are considered below and will be used as the boundary conditions for diffusion calculations.

\subsubsection{Meier model}

The oxidation model proposed by Meier et al. [21] was examined, in which they reported an oxide growth model in the form of a power law kinetics as given in Eq. (2),

$$
\delta_{(\mu m)}=\left\{\exp \left[Q\left(\frac{1}{T_{0}}-\frac{1}{T}\right)\right] t\right\}^{n}
$$

where $Q, T_{0}, T, t, n$ are activation energy constant, temperature constant, absolute oxidation temperature, exposure time and oxidation constant respectively. $Q, T_{0}$ and $n$ were found to be 27777.4 K, $2423.7 \mathrm{~K}$ and 0.332 respectively when $\delta$ is given in $\mu \mathrm{m}$ by fitting the experimental 
data between $1038 \sim 1149^{\circ} \mathrm{C}$ [21]. The oxide growth rate in $\mu \mathrm{m} / \mathrm{s}$ can be obtained by taking the first derivative of Eq. (2) with respect to time as expressed in Eq. (3).

$$
\dot{\delta}_{(\mu m / s)}=n\left\{\exp \left[Q\left(\frac{1}{T_{0}}-\frac{1}{T}\right)\right]\right\}^{n} t^{n-1}
$$

\subsubsection{TGA model}

Oxide growth kinetics can also be approached from the TGA analysis, using the weight gain per unit area divided by the density of the oxide, as shown in Eq. (4),

$$
\delta_{(\mu m)}=\frac{\Delta m}{A \rho_{o x}} \sim \sqrt{t}
$$

where $\rho_{o x}$ is the density of the oxide, taken as the density of $\mathrm{Al}_{2} \mathrm{O}_{3}\left(3950 \mathrm{~kg} / \mathrm{m}^{3}\right)$. For freestanding coatings used in this study, the weight gain obtained is assumed from the $\mathrm{Al}_{2} \mathrm{O}_{3}$ that forms on the as-sprayed rough surface and the debonded surface. Since the surface roughness can affect the weight gain under different surface conditions, thus the weight gain on a specific surface, i.e. the rough surface, can be rewritten as,

$$
\frac{\Delta m}{A} \times \frac{R_{a}(\text { rough })}{R_{a}(\text { total })}=\left(K_{p} t\right)^{\frac{1}{2}}
$$

where $K_{p}$ is parabolic rate constant in $\mathrm{g}^{2} / \mathrm{cm}^{4} / \mathrm{s}$ determined from the TGA analysis by the best fit of the parabolic law and $\mathrm{R}_{\mathrm{a}}$ (total) is the sum of surface roughness from the rough surface and debonded surface. By combining Eq. (4) and (5), the oxide growth kinetics at the rough surface can be approximated as

$$
\delta_{(\mu m)}=\frac{\Delta m}{A \rho_{o x}} \times \frac{R_{a}(\text { rough })}{R_{a}(\text { total })}=\frac{\left(K_{p} t\right)^{\frac{1}{2}}}{\rho_{o x}}
$$

Similarly to Eq. (3), the oxide growth rate can be given as Eq. (7).

$$
\dot{\delta}_{(\mu m / s)}=\frac{1}{2 \rho_{o x}}\left(\frac{K_{p}}{t}\right)^{\frac{1}{2}}
$$




\subsubsection{Experimentally fitted model}

An experimentally fitted oxide growth model was proposed, in which the thickness of the oxide scale after high temperature oxidation were measured by image analysis using the area of the alumina scale divided by the image width of $\sim 60 \mu \mathrm{m}$ in at least 5 SEM micrographs and were fitted to a power law oxide growth kinetics in Eq. (8),

$$
\delta_{(\mu m)}=B \cdot t^{\lambda}
$$

where B and $\lambda$ are constants. The oxide growth rate can then be presented as Eq. (9) by taking the differential of Eq. (8).

$$
\dot{\delta}_{(\mu m / s)}=B \cdot \lambda \cdot t^{\lambda-1}
$$

\subsubsection{Al flux}

The Al flux, $J_{A l}$, in the diffusion model as the boundary condition is determined by Eq. (10) through a mass balance conversion,

$$
J_{A l}=\dot{\delta} \cdot \rho_{o x} \cdot r
$$

where $\dot{\delta}$ is the oxide growth rate obtained from the above oxidation models and $r$ is the ratio in mass balance conversion from $\mathrm{Al}_{2} \mathrm{O}_{3}$ to $\mathrm{Al}$. The coating surface recession is very slow due to the mechanism of the growth of alumina, it is thus neglected in the current work [44].

\subsection{Diffusion modelling}

\subsubsection{Initial conditions}

$1 \mu \mathrm{m}$ initial oxide is assumed to have formed during heat treatment and, to account for this, an initial $\beta$ depletion zone of $5.6 \mu \mathrm{m}$ is imposed. Previous work has shown that this assumption agrees well with the experimental observations during the initial $2 \mathrm{~h}$ heat treatment at $1100{ }^{\circ} \mathrm{C}$ [41]. The time to allow $1 \mu \mathrm{m}$ oxide to form under the above three oxide growth kinetics are summarised in Table 1 . In the initial $\beta$ depletion zone, the $\gamma$ phase composition at $1100{ }^{\circ} \mathrm{C}$ is 
used as the elemental composition. In the $\gamma+\beta$ region, the powder composition is used as the overall composition of the coating.

\subsubsection{Boundary conditions}

The boundary condition for the diffusion model is the Al flux functions based on oxide growth models. The starting aluminium flux used is when $1 \mu \mathrm{m}$ oxide has formed as summarised in Table 1 , where $t_{1}$ is the time to achieve $1 \mu \mathrm{m}$ oxide. Subsequently the Al flux, $\mathrm{J}_{\mathrm{Al}}$, follows Eq. (10) under different oxide growth kinetics in the diffusion calculations, as illustrated schematically in Fig. 1. Combining the previous work [20, 45, 46], a labyrinth factor was incorporated here in Eq. (11) to accommodate the effects of non-diffusional $\beta$-NiAl phase which was defined by TTNi7 thermodynamic database,

$$
\frac{D_{e f f}^{\text {upper }}}{D_{\gamma}}=1+\frac{3-3 f_{\gamma}}{f_{\gamma}-\frac{10}{3}}
$$

where $D_{\gamma}$ and $f_{\gamma}$ are the diffusivity and volume fraction of the $\gamma$ phase respectively. Lattice diffusion is considered and grain boundary diffusion is neglected. Diffusion calculations using the nickel superalloy thermodynamic database, TTNi7, and the kinetic mobility database, MOB2, were performed with DICTRA software [47-49]. A fully implicit solution method was used with a time step of $1000 \mathrm{~s}$ at $1100{ }^{\circ} \mathrm{C}$ for $250 \mathrm{~h}$.

\section{Results}

\subsection{Microstructural analysis}

The microstructure of the vacuum heat treated free-standing CoNiCrAlY coatings is shown in Fig. 2. It can be seen from Fig. 2(a) that there is very little porosity apparent in the coating. A two-phase microstructure, consisting of the light contrast fcc- $\gamma$ Ni-rich matrix phase and the dark contrast bcc- $\beta(\mathrm{Co}, \mathrm{Ni}) \mathrm{Al}$ secondary phase is seen in Fig 2(b). The volume fraction of the 
uniformly distributed $\beta$ phase was found to be around $30 \%$ by image analysis, which has an equivalent mass fraction of around $25 \%$ through a mass balance conversion. Micron sized, dark contrast particles that were mainly found around powder particle boundaries as either discrete particles or thin stringers are also visible in Fig. 2(c). Chemical analysis showed them to be aluminium rich oxides that formed by oxidation of powders during the HVOF spraying process. It is clear From Fig. 2 that their volume fraction is less than $1 \%$ in the coating. Fig. 3 shows EBSD-derived inverse pole figure and phase distribution maps for vacuum heat treated coatings. It can be seen that the $\gamma$ grains are generally twinned and the $\beta$ grains are monocrystalline grains in the coating. Coarse grain regions within the particles and fine grain regions around the particle boundaries are found to exist. This can be attributed to the molten particles collide with the splats and high cooling rate occurred at the particle boundaries. The high impact force generated from high velocity collision between the splats can mechanically deform the splats and recrystallization occurred around the molten particle boundaries, causing the fine grains to form. The coarse grains were retained as the original particle microstructure during HVOF thermal spraying. Grain size ranges from $1 \sim 2 \mu \mathrm{m}$ in the coarse grain regions and about $\sim 500 \mathrm{~nm}$ or even less in the fine grain regions. The random assortment of colour in Fig. 3(a) indicates that no preferred orientation was present in either $\gamma$ or $\beta$ phases.

\subsection{High temperature oxidation}

During oxidation, the $\mathrm{Al}$ content decreases due to the outward diffusion of $\mathrm{Al}$ from the coating, allowing the protective oxides to form at the coating surface. As previously reported, the initial heat treatment promotes the alumina scale growth rather than spinel oxides [38]. This is shown typically in Fig. 4, demonstrating the main oxide is alumina. The loss of Al in the coating causes the growth of a single $\gamma$ phase zone below the protective alumina scale. This $\gamma$ zone is termed the $\beta$-phase depletion zone, as depicted in Fig. 4. The mass gain per unit 
area as a function of time for the heat treated coating obtained from the TGA is shown in Fig. 5. The total weight gain of the coating (Eq. (1)) and the approximated weight gain for the rough surface (Eq. (5)) are included in this figure. It is found from Fig. 5 that the TGA results generally exhibit a parabolic law and the parabolic rate constant derived from Eq. (5) is $5.02 \times$

$10^{-12} \mathrm{~g}^{2} / \mathrm{cm}^{4} / \mathrm{s}$. The experimentally measured oxide thickness against the oxidation time and the corresponding $\beta$-phase depletion zone are summarised in Fig. 6 . The oxide growth at the rough surface shown in Fig. 6 was used to fit with a power law oxide growth kinetics (Eq. (8)) as shown in Fig. 7 , in which the B and $\lambda$ are found to be $2.9 \times 10^{-4}$ and 0.715 respectively.

\subsection{Modelling results}

Fig. 7 shows the oxide growth behaviour of the three different oxidation models. It can be seen that the oxide thickness calculated from Meier model are the largest, followed by the TGA model, and the experimentally fitted model shows the smallest oxide thickness. They all yield at $\sim 5 \mu \mathrm{m}$ after $250 \mathrm{~h}$ at $1100{ }^{\circ} \mathrm{C}$. Oxide growth rates, Eq. (3), (7) and (9), derived from the corresponding oxide growth models are presented in Fig. 8(a). The Meier model exhibits higher oxide growth rate within the first $25 \mathrm{~h}$, but after that the growth rate from the fitted model becomes larger. According to Eq. (10) the Al flux is proportional to the oxide growth rate, as shown similarly in Fig. 8(b). Al content decreases as the time progresses due to the $\mathrm{Al}$ flux at the boundary in the diffusion modelling. The Al profiles after $100 \mathrm{~h}$ oxidation are shown in Fig. 9. The Al content is calculated to be $\sim 4.8 \mathrm{wt} \%$ in the $\beta$ depletion zone, close to the $\gamma$ phase composition. In the $\gamma+\beta$ region, the $\mathrm{Al}$ content is about $8.1 \mathrm{wt} \%$, representing the overall coating composition. Fig. 10 depicts the phase fractions after $100 \mathrm{~h}$, where a larger $\beta$ phase depletion zone is seen in the Meier model. Since the loss of Al alters the chemical potentials of other elements in the coating, the element composition profiles under different oxidation models are compared with EDX measurements in Fig. 11 after 100 h oxidation. Generally, the element concentrations predicted from the diffusion modelling show good 
agreements with experimental measurements though the $\beta$ depletion zones obtained from each model are different. The comparison of the $\beta$-phase depletion from the modelling results and experimental measurements are shown in Fig. 12 for times up to $250 \mathrm{~h}$ at $1100{ }^{\circ} \mathrm{C}$. It can be seen that the $\beta$-phase depletion obtained the three models exhibit good agreements with experimental results for times up to $100 \mathrm{~h}$ though the Meier model shows larger $\beta$-phase depletion and the experimentally fitted model exhibits less $\beta$-phase depletion. Discrepancies between modelling and experimental results were noted at $250 \mathrm{~h}$.

\section{Discussion}

\subsection{Oxide growth kinetics}

Since the elemental diffusion kinetics, especially Al, is driven by the oxidation models used, the oxide growth kinetics are crucial to the lifing aspects of MCrAlY coatings. Meier model was previously developed on a NiCoCrAlY bond coat $(\mathrm{Ni}-22.0 \% \mathrm{Co}-17.0 \% \mathrm{Cr}-12.5 \% \mathrm{Al}-$ $0.6 \% \mathrm{Y}$, all in wt $\%$ ) with a $\gamma+\beta$ structure deposited by air plasma spraying. It has been reported that the oxidation behaviour of plasma sprayed and HVOF sprayed MCrAlY coatings are different [38, 50]. The oxide growth behaviour can also vary with the composition used [25]. Thus Fig. 7 and Fig. 8 show the variations of the Meier model compared to the other two models used in this study. The parabolic constant obtained from TGA analysis agrees well with other reported work in the literature [51-53], with magnitudes between $10^{-10} \sim 10^{-14}$ depending on the temperatures used. Since Meier model was based on the as-sprayed surface, the comparisons with other models were conducted under rough surface conditions. The experimentally fitted oxide growth model was presented in the form of a simplified power law kinetics. This fitted model does not show strictly parabolic oxidation kinetics and the least oxide thickness was obtained. Nevertheless, these models can act as typical models for the oxidation of MCrAlY coatings. Al flux shown in Fig. 8(b) is the boundary condition used for diffusion calculations. Before the diffusion calculation starts, an 
initial alumina scale was assumed to exist to avoid infinite value of $\mathrm{Al}$ flux at the boundary. The starting Al fluxes for each model are summarised in Table 1 according to Fig. 1, which depends on the time to allow $1 \mu \mathrm{m}$ oxide to form based on the oxide growth kinetics of each model. When the time progresses, the oxide gets thicker and the activity at the coating surface decreases, this agrees well with the fact that the Al flux decreases with time as shown in Fig. 8(b).

\subsection{Evolution of $\beta$-phase depletion}

The $\beta$-phase depletion occurred, as expected, faster at higher oxidation kinetics. The Al flux obtained from Meier model is larger than the other two models in the first $25 \mathrm{~h}$ and becomes smaller after that as seen in Fig. 8. The larger Al flux obtained from Meier model in the first $25 \mathrm{~h}$ dominates the subsequent $\mathrm{Al}$ loss and the resultant $\beta$-phase depletion. It should be noted that the Al flux becomes very small, less than $1 \times 10^{-6} \mathrm{~mol} / \mathrm{m}^{2} / \mathrm{s}$, after $25 \mathrm{~h}$. The higher oxidation rate obtained from the Meier model indicates the higher loss of $\mathrm{Al}$ and as a result, larger $\beta$-phase depletion zone is formed. The $\mathrm{Al}$ content and phase fractions shown in Fig. 9 and Fig. 10 respectively further support this view. Correspondingly, the element composition profiles shown in Fig. 11 present the element concentration distribution under three oxidation models. Since the boundary condition is limited to the Al flux, the rate of Al loss dominates the growth of the $\beta$-phase depletion zone. Other elements, like $\mathrm{Co}, \mathrm{Ni}$ and $\mathrm{Cr}$ are altered accordingly due to the changes of chemical potential which partially depends on the element concentrations in the system, though small discrepancies of $\mathrm{Co}, \mathrm{Ni}$ and $\mathrm{Cr}$ were found which is likely due to the difference between the thermodynamic database and experimental measurements [41].

The comparison of the $\beta$-phase depletion zone between modelling and experimental results,

Fig. 12, shows that the TGA model appears to be more suitable for times up to $100 \mathrm{~h}$. However, discrepancies were seen after longer period of oxidation, i.e. $250 \mathrm{~h}$. It can be seen 
that the experimentally determined TGO thickness is slightly larger than the models at $250 \mathrm{~h}$ in Fig. 7, whereas the $\beta$ depletion zone obtained from the experimental measurements is smaller compared to the model predictions at $250 \mathrm{~h}$ in Fig. 12. That means the coating is experiencing a much smaller Al flux during isothermal oxidation at this stage. It can be attributed to a few factors. The oxidation models used may not be able to fully represent the actual oxidation kinetics that occurred to the coating, especially at longer exposure time. It has been reported that a critical oxide thickness may exist during oxidation for TBCs and the oxide layer that beyond this critical value will start to spall off $[9,11]$. It is usually found that the critical thickness is around $6 \mu \mathrm{m}$, which is also the case seen from Fig. 7 at $250 \mathrm{~h}$. However, the spallation of TGO will accelerate the $\beta$-phase depletion since the formation and growth of new TGOs will further consume the $\mathrm{Al}$ and the $\beta$ phase in the coating. But on the contrary, a smaller $\beta$-phase depletion zone is seen from experimental observations at $250 \mathrm{~h}$, indicating that the spallation of TGO may not yet occur. It is thus believed that at this stage when approaching the critical oxide thickness, the Al flux may become very slow and, as a result, smaller $\beta$-phase depletion zone is obtained from the experimental measurements than model predictions at $250 \mathrm{~h}$. Although it is proposed that the Al flux becomes very small when approaching the critical oxide thickness, the fine scale oxide particles and stringers seen in Fig. 2 may also have a role in affecting the $\beta$-phase depletion. These alumina stringers can act as effective diffusion barriers which exhibit blocking effects for element diffusion [23]. Furthermore, the labyrinth factor introduced in this study can also influence the resultant element diffusion and $\beta$-phase depletion. The labyrinth factor is employed to account apparent diffusion due to the presence of $\beta$ phases, but it is limited to the lattice diffusion of the $\gamma$ matrix. The actual diffusion in the $\gamma+\beta$ phase can be much slower due to the high volume fraction of the $\beta$ phase. Consequently, the net effect of the above would be a smaller $\beta$ depletion zone as is indeed observed in Fig. 12. 


\subsection{Comparison with previous studies}

It is widely recognised that higher oxide thickness would produce a larger $\beta$-phase depletion zone, as evidenced by Fig. 7 and Fig. 12. When using the Meier model, it has been found that it shows higher oxidation rate compared to experimental observations by Karunaratne et al. [20]. Thus the Meier model may not be very appropriate for the CoNiCrAlY coating used in this study. The deviation from Meier model could also be attributed to the use of fitting parameters which was derived from oxidation tests on a different MCrAlY coating deposited using a different thermal spray technique. This could produce discrepancies compared to experimental results here as the oxidation behaviour of MCrAlY coatings largely depends on the microstructure and the deposition method. The approach of using experimentally fitted oxide growth kinetics was also proposed by Yuan et al. [23] and Eriksson et al. [24] for diffusion boundary conditions. In their studies, they used a parabolic law to fit the oxide growth, but in the present study it was found that the obtained oxide thickness did not strictly follow the parabolic growth law and exhibited lower oxidation rate. The TGA model incorporated with the surface roughness effects shows better agreement among the three models and a parabolic $\beta$-phase depletion behaviour is found, similar to other analytical models developed for the two-phase alloy systems [54-57]. However, previous studies have either been conducted with different MCrAlY compositions or involve interdiffusion between the coating and substrate. Thus direct comparison with other studies is not applicable. The study presents here concerns the oxide growth and $\beta$-phase depletion on free-standing MCrAlY coatings and is believed to be useful as a step towards studying the coating-substrate system after all the conditions have been established for the free-standing coatings.

\section{Conclusions}

- A two-phase structure in this HVOF CoNiCrAlY coating is found to exist, the fcc- $\gamma$ phase exhibit a twinned grain structure and the bcc- $\beta$ phase is monocrystalline. Coarse 
grain regions are retained within the sprayed particles and fine grain regions are found around the particle boundaries.

- Three oxidation models were examined, namely the Meier model, the TGA model and experimentally fitted model. It is shown that the Meier model exhibits the largest oxidation kinetics, followed by the TGA model, and the experimentally fitted model shows the least oxidation kinetics.

- The evolution of $\beta$-phase depletion obtained from the three oxidation models shows reasonable agreements with experimental measurements for times up to $100 \mathrm{~h}$ at 1100 ${ }^{\circ} \mathrm{C}$ but discrepancies are seen at $250 \mathrm{~h}$. The deviation is likely related to the difference in the modelled and actual oxidation kinetics over the whole oxidation period as well as the difference in the modelled and actual diffusion behaviour. Further work on modifying the oxidation kinetics and incorporating the diffusion block effects and effective diffusion coefficients in the model will be needed to improve the predictions at longer exposure times.

\section{Acknowledgements}

The authors would like to thank Prof. John Nicholls and Dr. Katy Voisey for helpful discussions. The authors would like to acknowledge Faculty of Engineering, University of Nottingham for provision of laboratory facilities. We would also like to thank Loughborough University and Dr. G. West for assistance with the EBSD study. The financial support from Nature Science Foundation of China (No. 21403119), Zhejiang Natural Science Foundation Programme (No. LQ16E060001), Zhejiang Commonweal Technology Project (No. 2016C31023), Ningbo Enrich People Project (2016C10035) and Ningbo Natural Science Foundation Programme (No. 2016A610114) are acknowledged.

\section{References}


[1] J.R. Nicholls, Designing oxidation-resistant coatings, JOM, 52 (2000) 28-35.

[2] G.W. Goward, Progress in coatings for gas turbine airfoils, Surf. Coat. Technol., 108-109 (1998) 73-79.

[3] J.R. Nicholls, K.J. Lawson, D.S. Rickerby, P. Morrell, Advanced processing of TBCs for reduced thermal conductivity, AGARD Report 823 "Thermal Barrier Coatings" (1998).

[4] A.G. Evans, D.R. Mumm, J.W. Hutchinson, G.H. Meier, F.S. Pettit, Mechanisms controlling the durability of thermal barrier coatings, Prog. Mater Sci., 46 (2001) 505-553.

[5] D. Stöver, C. Funke, Directions of the development of thermal barrier coatings in energy applications, J. Mater. Process. Technol., 92-93 (1999) 195-202.

[6] T. Nijdam, W. Sloof, Effect of Y Distribution on the Oxidation Kinetics of NiCoCrAlY Bond Coat Alloys, Oxid. Met., 69 (2008) 1-12.

[7] A. Gil, D. Naumenko, R. Vassen, J. Toscano, M. Subanovic, L. Singheiser, W.J.

Quadakkers, Y-rich oxide distribution in plasma sprayed MCrAlY-coatings studied by SEM with a cathodoluminescence detector and Raman spectroscopy, Surf. Coat. Technol., 204 (2009) 531-538.

[8] S. Bose, High Temperature Coatings, Elsevier Butterworth-Heinemann, Oxford, 2007.

[9] J. Toscano, D. Naumenko, A. Gil, L. Singheiser, W.J. Quadakkers, Parameters affecting TGO growth rate and the lifetime of TBC systems with MCrAlY-bondcoats, Mater. Corros., 59 (2008) 501-507.

[10] Y. Li, C.-J. Li, Q. Zhang, L.-K. Xing, G.-J. Yang, Effect of Chemical Compositions and Surface Morphologies of MCrAlY Coating on Its Isothermal Oxidation Behavior, J. Therm. Spray Technol., 20 (2010) 121-131.

[11] D. Naumenko, V. Shemet, L. Singheiser, W. Quadakkers, Failure mechanisms of thermal barrier coatings on MCrAlY-type bondcoats associated with the formation of the thermally grown oxide, J. Mater. Sci., 44 (2009) 1687-1703.

[12] J. Toscano, R. Vaen, A. Gil, M. Subanovic, D. Naumenko, L. Singheiser, W.J.

Quadakkers, Parameters affecting TGO growth and adherence on MCrAlY-bond coats for TBC's, Surf. Coat. Technol., 201 (2006) 3906-3910.

[13] E.A.G. Shillington, D.R. Clarke, Spalling failure of a thermal barrier coating associated with aluminum depletion in the bond-coat, Acta Mater., 47 (1999) 1297-1305.

[14] N. Czech, F. Schmitz, W. Stamm, Improvement of MCrAlY coatings by addition of rhenium, Surf. Coat. Technol., 68-69 (1994) 17-21.

[15] N. Czech, F. Schmitz, W. Stamm, Microstructural analysis of the role of rhenium in advanced MCrAlY coatings, Surf. Coat. Technol., 76-77 (1995) 28-33.

[16] C.E. Lowell, C.A. Barrett, R.W. Palmer, J.V. Auping, H.B. Probst, COSP: A computer model of cyclic oxidation, Oxid. Met., 36 (1991) 81-112.

[17] J.A. Nesbitt, COSIM-a finite difference computer model to predict ternary concentration profiles associated with oxidation and interdiffusion of overlay-coated substrates, Technical Report No. NASA/TM-2000-209271, (2000).

[18] E.Y. Lee, D.M. Chartier, R.R. Biederman, R.D. Sisson, Modelling the microstructural evolution and degradation of M-Cr-Al-Y coatings during high temperature oxidation, Surf. Coat. Technol., 32 (1987) 19-39.

[19] D.R.G. Achar, R. Munoz-Arroyo, L. Singheiser, W.J. Quadakkers, Modelling of phase equilibria in MCrAlY coating systems, Surf. Coat. Technol., 187 (2004) 272-283.

[20] M.S.A. Karunaratne, S.L. Ogden, S.D. Kenny, R.C. Thomson, A multicomponent diffusion model for prediction of microstructural evolution in coated Ni based superalloy systems, Mater. Sci. Technol., 25 (2009) 287-299.

[21] S.M. Meier, D.M. Nissley, K.D. Sheffler, Thermal barrier coating life prediction model development, Phase 2 Final Report, Technical Report NASA Contractor Report 18911/NAS323944, (1991). 
[22] R. Pillai, W.G. Sloof, A. Chyrkin, L. Singheiser, W.J. Quadakkers, A new computational approach for modelling the microstructural evolution and residual lifetime assessment of MCrAlY coatings, Mater. High Temp., 32 (2015) 57-67.

[23] K. Yuan, R. Eriksson, R. Lin Peng, X.-H. Li, S. Johansson, Y.-D. Wang, Modeling of microstructural evolution and lifetime prediction of MCrAlY coatings on nickel based superalloys during high temperature oxidation, Surf. Coat. Technol., 232 (2013) 204-215. [24] R. Eriksson, K. Yuan, X.-H. Li, R. Lin Peng, MCrAlY coating design based on oxidation-diffusion modelling. Part II: Lifing aspects, Surf. Coat. Technol., 253 (2014) 27-37. [25] K. Yuan, R. Lin Peng, X.-H. Li, S. Johansson, Y.-D. Wang, Some aspects of elemental behaviour in HVOF MCrAlY coatings in high-temperature oxidation, Surf. Coat. Technol., 261 (2015) 86-101.

[26] M.S.A. Karunaratne, I. Di Martino, S.L. Ogden, D.L. Oates, R.C. Thomson, Modeling of Microstructural Evolution in an MCrAlY Overlay Coating on Different Superalloy Substrates, Metall. Mater. Trans. A, 43 (2011) 774-788.

[27] K. Yuan, R. Eriksson, R. Lin Peng, X.-H. Li, S. Johansson, Y.-D. Wang, MCrAlY coating design based on oxidation-diffusion modelling. Part I: Microstructural evolution, Surf. Coat. Technol., 254 (2014) 79-96.

[28] Y. Li, C.-J. Li, G.-J. Yang, L.-K. Xing, Thermal fatigue behavior of thermal barrier coatings with the MCrAlY bond coats by cold spraying and low-pressure plasma spraying, Surf. Coat. Technol., 205 (2010) 2225-2233.

[29] H. Chen, T.H. Hyde, K.T. Voisey, D.G. McCartney, Effects of pre-cracking on small punch creep testing of a vacuum plasma-sprayed CoNiCrAlY coating, Proc IMechE Part L: J Materials: Design and Application, DOI 10.1177/1464420715622495 (2016).

[30] D. Seo, K. Ogawa, T. Shoji, S. Murata, High-temperature Oxidation Behavior and Surface Roughness Evolution of VPS NiCrAlY Coating, J. Therm. Spray Technol., 17 (2008) 136-143.

[31] P. Poza, P.S. Grant, Microstructure evolution of vacuum plasma sprayed CoNiCrAlY coatings after heat treatment and isothermal oxidation, Surf. Coat. Technol., 201 (2006) 28872896.

[32] A. Rabiei, A.G. Evans, Failure mechanisms associated with the thermally grown oxide in plasma-sprayed thermal barrier coatings, Acta Mater., 48 (2000) 3963-3976.

[33] H. Chen, D.G. McCartney, K.T. Voisey, Effect of surface conditions on internal oxidation and nitridation of HVOF MCrAlY coatings, Mater. High Temp., 32 (2015) 215-220. [34] M. Tahari, M. shamanian, M. salehi, The effect of heat treatment and thermal spray processes on the grain growth of nanostructured composite CoNiCrAlY/YSZ powders, J. Alloys Compd., 646 (2015) 372-379.

[35] T. Mori, S. Kuroda, H. Murakami, H. Katanoda, Y. Sakamoto, S. Newman, Effects of initial oxidation on $\beta$ phase depletion and oxidation of CoNiCrAlY bond coatings fabricated by warm spray and HVOF processes, Surf. Coat. Technol., 221 (2013) 59-69.

[36] H. Chen, T.H. Hyde, K.T. Voisey, D.G. McCartney, Application of small punch creep testing to a thermally sprayed CoNiCrAlY bond coat, Mater. Sci. Eng. A, 585 (2013) 205-213. [37] A. Fossati, M. Di Ferdinando, A. Lavacchi, U. Bardi, C. Giolli, A. Scrivani, Improvement of the isothermal oxidation resistance of CoNiCrAlY coating sprayed by High Velocity Oxygen Fuel, Surf. Coat. Technol., 204 (2010) 3723-3728.

[38] S. Saeidi, K.T. Voisey, D.G. McCartney, The Effect of Heat Treatment on the Oxidation Behavior of HVOF and VPS CoNiCrAlY Coatings, J. Therm. Spray Technol., 18 (2009) 209216.

[39] S. Saeidi, K.T. Voisey, D.G. McCartney, Mechanical Properties and Microstructure of VPS and HVOF CoNiCrAlY Coatings, J. Therm. Spray Technol., 20 (2011) 1-13.

[40] H. Chen, T.H. Hyde, Use of multi-step loading small punch test to investigate the ductile-to-brittle transition behaviour of a thermally sprayed CoNiCrAlY coating, Mater. Sci. Eng. A, 680 (2017) 203-209. 
[41] H. Chen, G.A. Jackson, K.T. Voisey, D.G. McCartney, Modelling and experimental study on $\beta$-phase depletion behaviour of HVOF sprayed free-standing CoNiCrAlY coatings during oxidation, Surf. Coat. Technol., 291 (2016) 34-42.

[42] H. Chen, Mechanical and chemical behaviour of thermally sprayed CoNiCrAlY bond coats, Ph.D Thesis, Department of Mechanical, Materials and Manufacturing Engineering, University of Nottingham, (2015).

[43] C.A. Schneider, W.S. Rasband, K.W. Eliceiri, NIH Image to ImageJ: 25 years of image analysis, Nat. Methods, 9 (2012) 671-675.

[44] L. Lelait, S. Alpérine, R. Mévrel, Alumina scale growth at zirconia-MCrAlY interface: a microstructural study, J. Mater. Sci., 27 (1992) 5-12.

[45] Z. Hashin, S. Shtrikman, A variational approach to the theory of the effective magnetic permeability of multiphase materials, J. Appl. Phys., 33 (1962) 3125-3131.

[46] T. Gómez-Acebo, B. Navarcorena, F. Castro, Interdiffusion in multiphase, Al-Co-Cr-NiTi diffusion couples, J Phs Eqil and Diff, 25 (2004) 237-251.

[47] J. Andersson, T. Helander, L. Höglund, P. Shi, B. Sundman, Thermo-Calc \& DICTRA, computational tools for materials science, Calphad, 26 (2002) 273-312.

[48] A. Borgenstam, L. Höglund, J. Ågren, A. Engström, DICTRA, a tool for simulation of diffusional transformations in alloys, J. Phase Equilib., 21 (2000) 269-280.

[49] N. Saunders, Phase diagram calculations for Ni-based superalloys, Superalloys 1996,

TMS, Warrendale, PA, USA, (1996) 101.

[50] M. Majid, J. Sirus, K. Akira, S. Korush, J.J. Ahmad, K. Iman, Cyclic Oxidation Behavior of CoNiCrAlY Coatings Produced by LVPS and HVOF Processes, Transaction of JWRI, 40 (2011) 53-58.

[51] N. Czech, M. Juez-Lorenzo, V. Kolarik, W. Stamm, Influence of the surface roughness on the oxide scale formation on MCrAlY coatings studied in situ by high temperature X-ray diffraction, Surf. Coat. Technol., 108-109 (1998) 36-42.

[52] W. Brandl, H.J. Grabke, D. Toma, J. Krüger, The oxidation behaviour of sprayed MCrAlY coatings, Surf. Coat. Technol., 86-87 (1996) 41-47.

[53] W. Brandl, D. Toma, H. Grabke, The characteristics of alumina scales formed on HVOFsprayed MCrAlY coatings, Surf. Coat. Technol., 108 (1998) 10-15.

[54] G. Wang, B. Gleeson, D.L. Douglass, An extension of Wagner's analysis of competing scale formation, Oxid. Met., 35 (1991) 317-332.

[55] F. Gesmundo, F. Viani, Y. Niu, D.L. Douglass, Further aspects of the oxidation of binary two-phase alloys, Oxid. Met., 39 (1993) 197-209.

[56] P. Carter, B. Gleeson, D. Young, Calculation of precipitate dissolution zone kinetics in oxidising binary two-phase alloys, Acta Mater., 44 (1996) 4033-4038.

[57] G. Wahl, Coating composition and the formation of protective oxide layers at high temperatures, Thin Solid Films, 107 (1983) 417-426. 
Table 1

The time to allow $1 \mu \mathrm{m}$ initial oxide to grow and the initial Al flux before the diffusion calculation starts, obtained from different oxidation models.

\begin{tabular}{c|c|c}
\hline Oxidation model & $\begin{array}{c}\text { Time for } 1 \mu \mathrm{m} \\
\text { initial oxide to } \\
\text { grow, } \mathrm{t}_{1}(\mathrm{~s})\end{array}$ & $\begin{array}{c}\text { Initial Al flux } \\
\left(\mathrm{mol} /\left(\mathrm{m}^{2} \mathrm{~s}\right)\right)\end{array}$ \\
\hline Meier model & 6441 & $4.00 \times 10^{-6}$ \\
\hline TGA model & 31100 & $1.25 \times 10^{-6}$ \\
\hline Fitted model & 88653 & $6.22 \times 10^{-7}$ \\
\hline
\end{tabular}




\section{Figures}



Fig. 1. Schematic diagram of $\mathrm{Al}$ flux at the boundary by assuming $1 \mu \mathrm{m}$ initial oxide thickness, $t_{1}$ is the time for the oxide to reach $1 \mu \mathrm{m}$ and the zero-time for the diffusion model with initial $1 \mu \mathrm{m}$ oxide thickness.

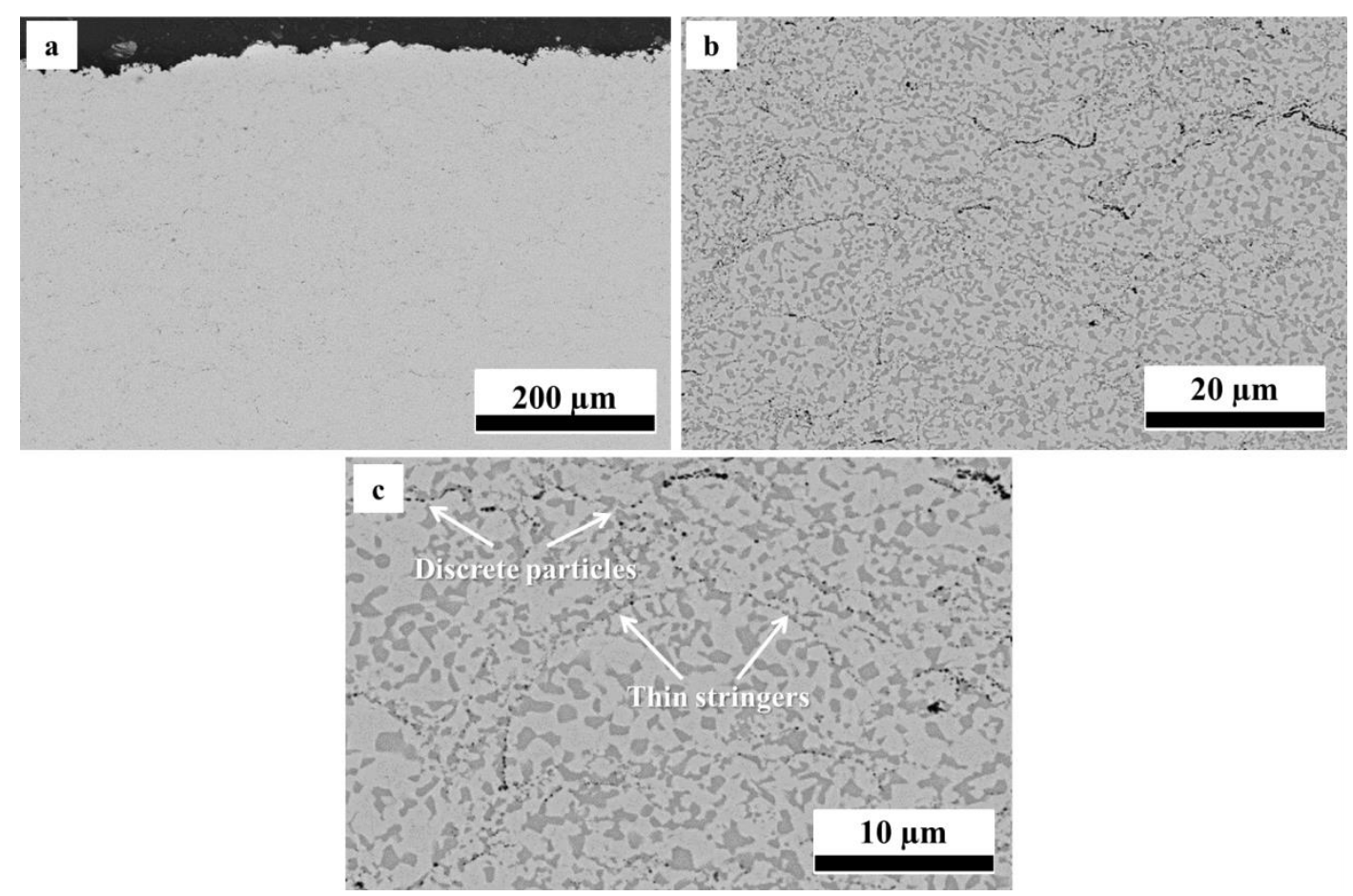

Fig. 2. Microstructure of vacuum heat-treated HVOF CoNiCrAlY coatings at $1100 \mathrm{C}$ for $2 \mathrm{~h}$ : (a) and (b) show the general microstructure, (c) shows the micron-sized discrete particles and thin oxide stringers. 

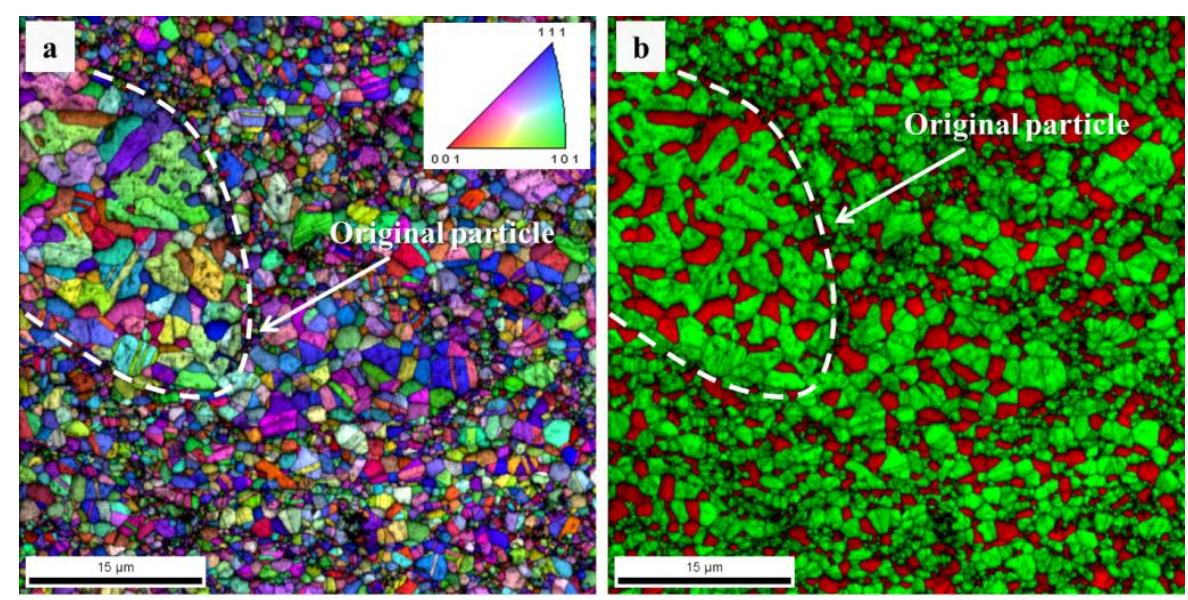

Fig. 3. EBSD-derived inverse pole figure (a) and phase distribution map (b) for the vacuum heat treated CoNiCrAlY coating. The $\beta$-phase is coloured red and the $\gamma$-phase green in (b).

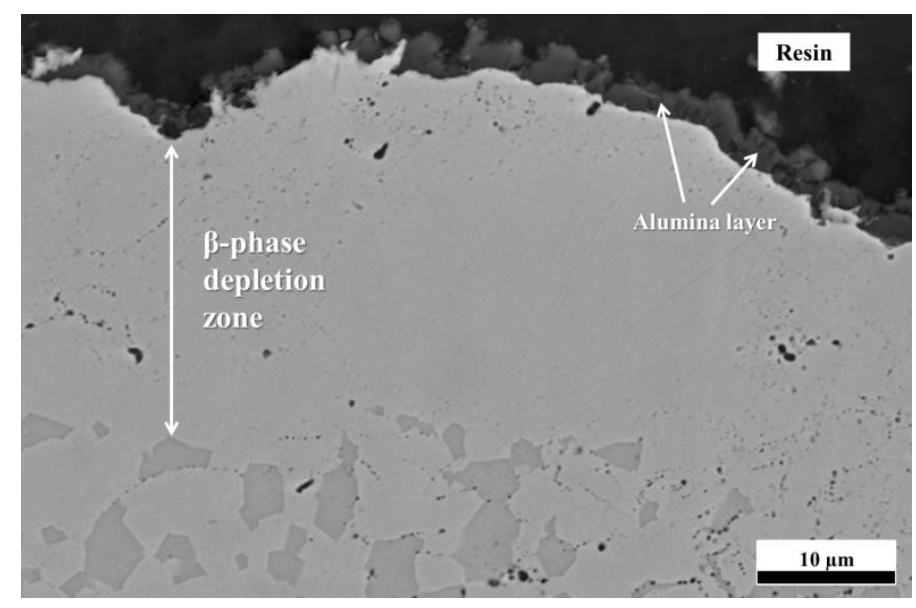

Fig. 4. A typical SEM micrograph showing the main oxide is alumina and the resultant $\beta$ phase depletion zone after $100 \mathrm{~h}$ oxidation at $1100^{\circ} \mathrm{C}$.

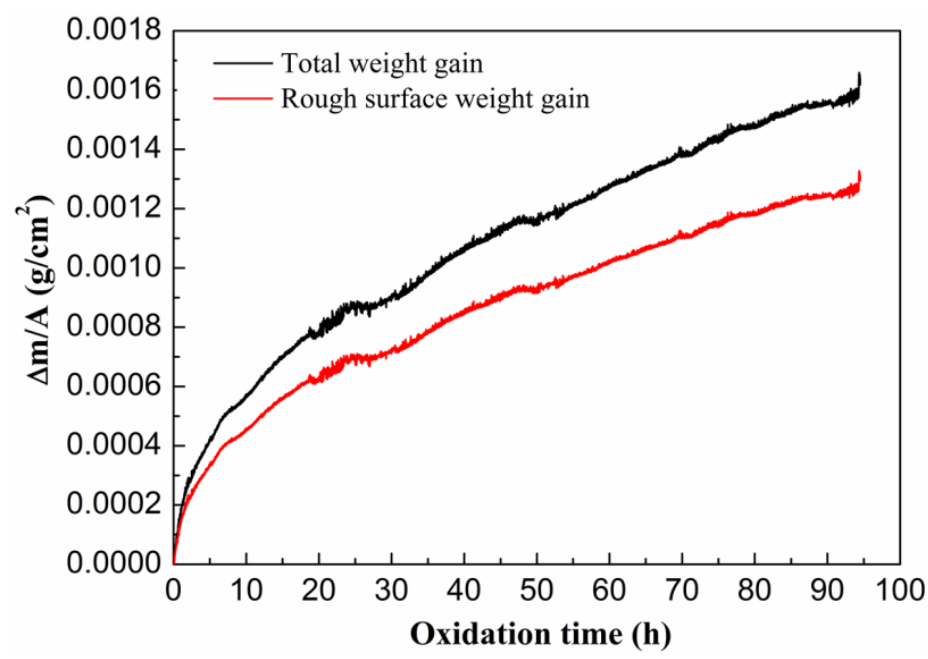

Fig. 5. Plot of total weight gain and rough surface weight gain versus time of heat treated CoNiCrAlY coating during oxidation at $1100^{\circ} \mathrm{C}$ for $95 \mathrm{~h}$. 


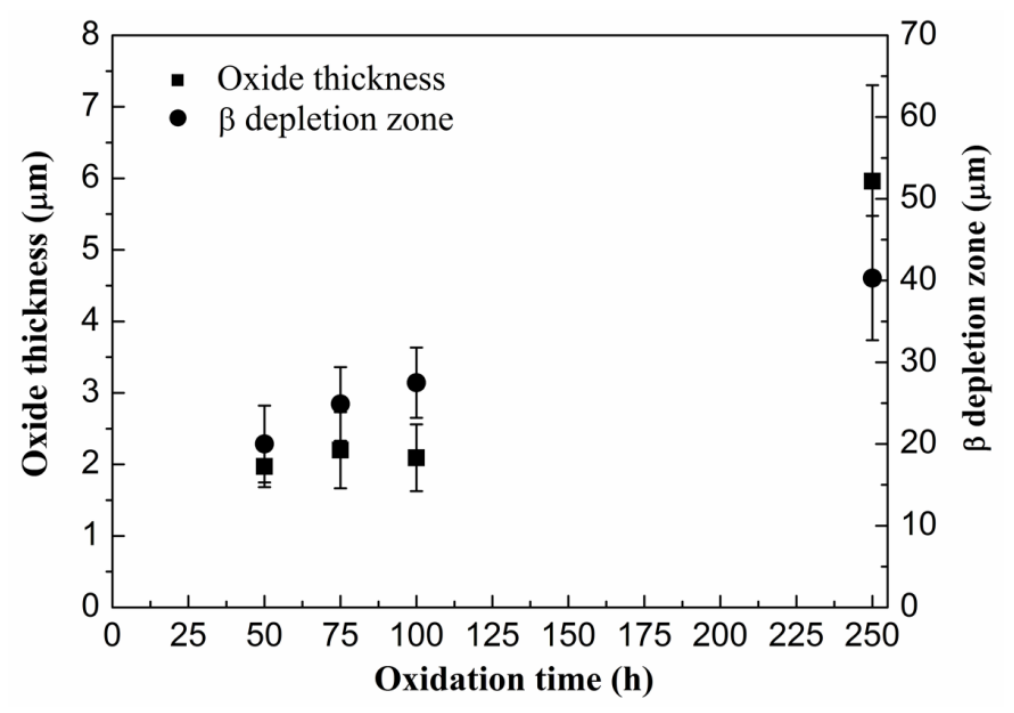

Fig. 6. Plot of experimentally measured oxide thickness and $\beta$ depletion zone versus oxidation times for $50 \mathrm{~h}, 75 \mathrm{~h}, 100 \mathrm{~h}$ and $250 \mathrm{~h}$ at $1100^{\circ} \mathrm{C}$.

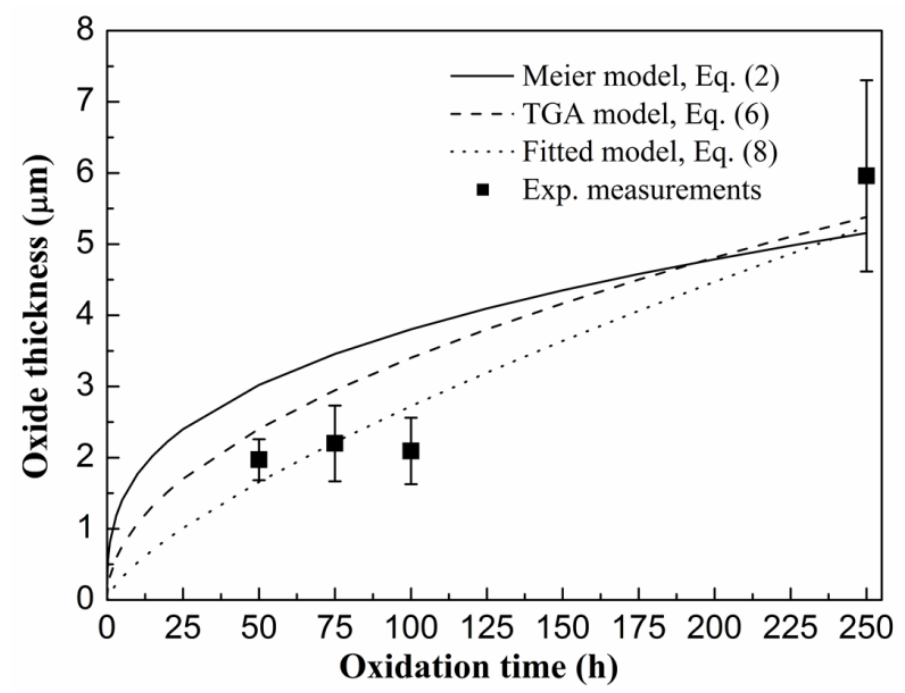

Fig. 7. Plot of calculated and experimentally measured oxide thickness versus oxidation time at $1100{ }^{\circ} \mathrm{C}$. 

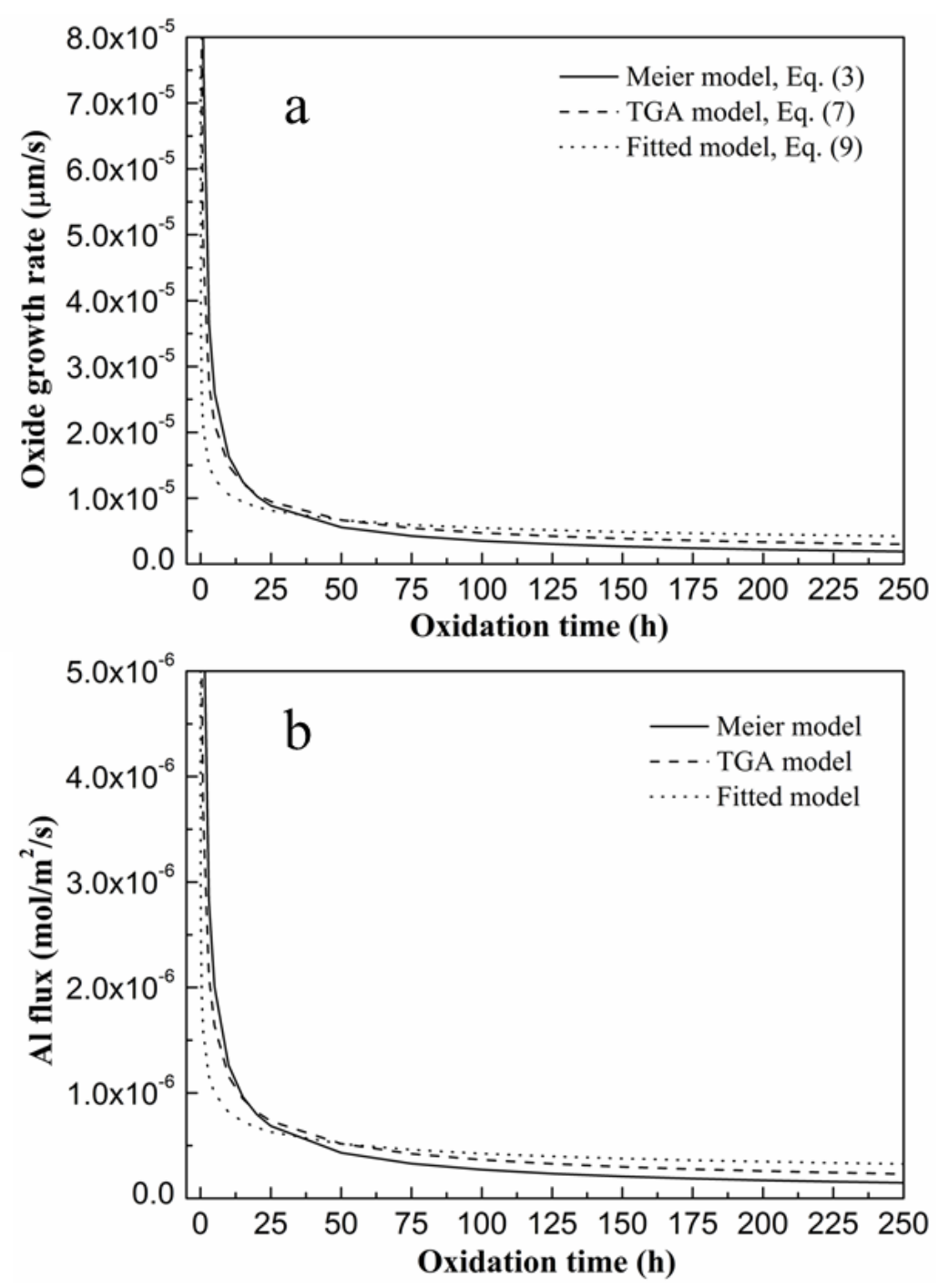

Fig. 8. Plot of oxide growth rate (a) and Al flux (b) obtained from different oxidation models versus time at $1100^{\circ} \mathrm{C}$.

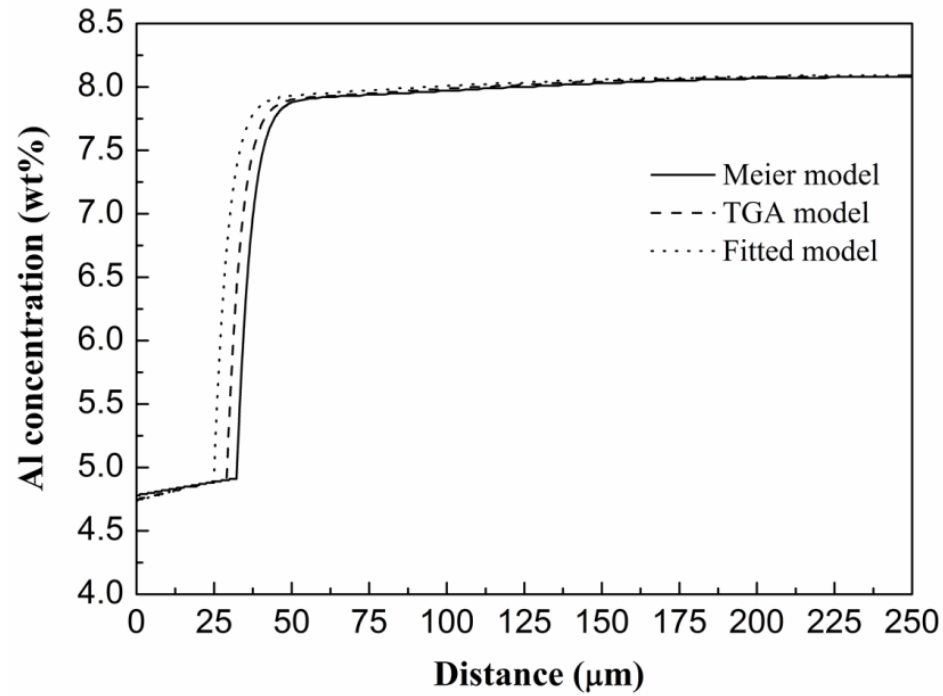

Fig. 9 . Plot of $\mathrm{Al}$ concentration versus distance from the oxide/coating interface at $1100{ }^{\circ} \mathrm{C}$ for $100 \mathrm{~h}$, showing the $\mathrm{Al}$ content near the interface is close to $4.8 \mathrm{wt} \%$. 


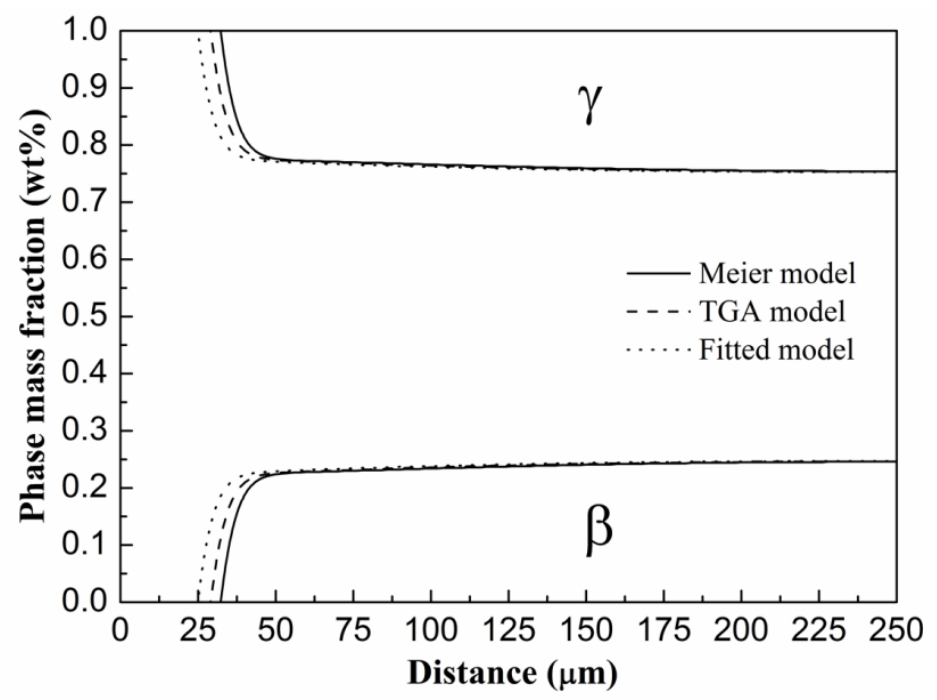

Fig. 10. Plot of phase mass fraction versus distance after $100 \mathrm{~h}$ at $1100{ }^{\circ} \mathrm{C}$ obtained from DICTRA calculations.
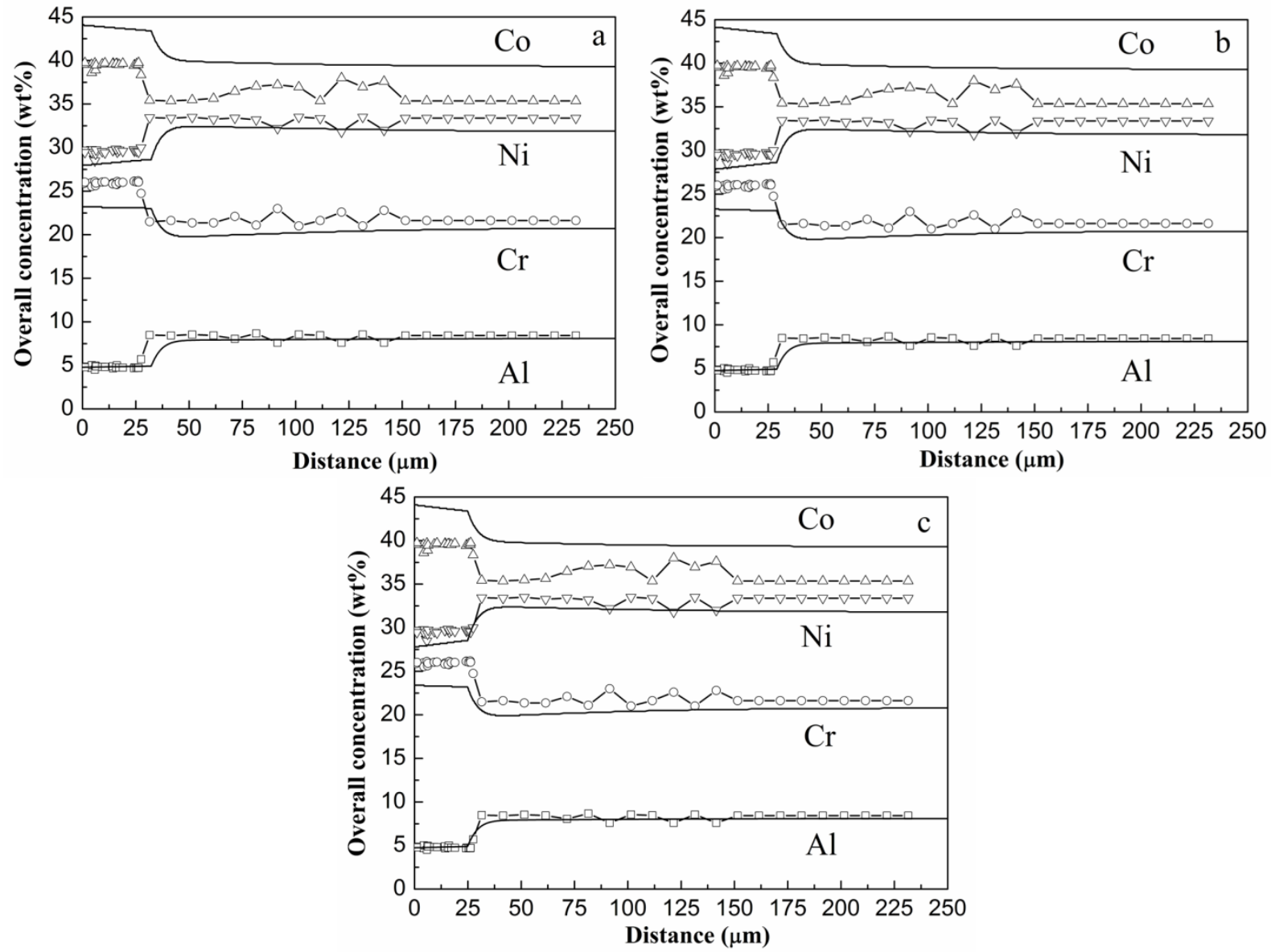

Fig. 11. Element composition profiles obtained from Meier model (a), TGA model (b) and Fitted model (c) at $1100{ }^{\circ} \mathrm{C}$ for $100 \mathrm{~h}$. The symbols are the EDX measurements. 


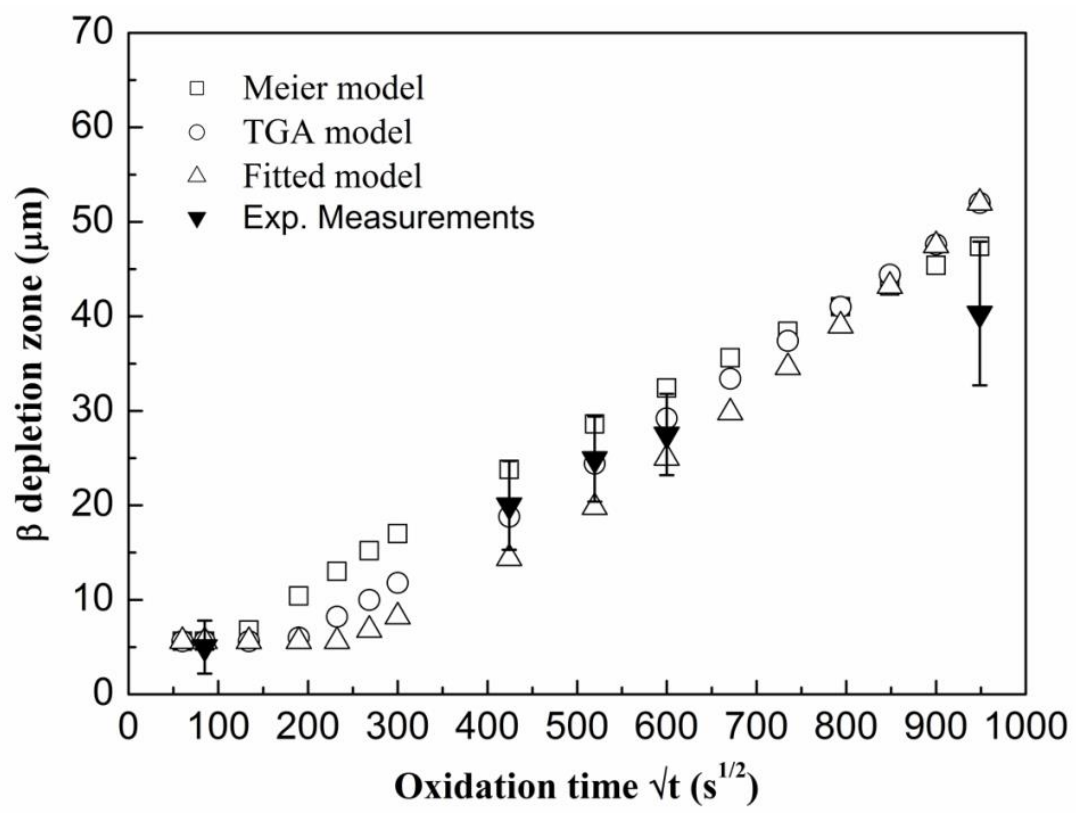

Fig. 12. Plot of the $\beta$-phase depletion zone versus time, zero-time is set for isothermal oxidation after initial heat treatment and for when the diffusion calculations start. An initial $\beta$ depletion zone of $5.6 \mu \mathrm{m}$ is assumed and the temperature is $1100^{\circ} \mathrm{C}$. 